\title{
Veia porta do preá (Galea spixii Wagler, 1831)
}

\author{
Gleidson Benevides de Oliveira ${ }^{1 *}$ \\ Márcio Nogueira Rodrigues ${ }^{2}$ \\ Roberto Sávio Bessa da Silva ${ }^{1}$ \\ José Fernando Gomes de Albuquerque ${ }^{3}$ \\ Maria Angélica Miglino ${ }^{2}$ \\ Moacir Franco de Oliveira ${ }^{1}$ \\ ${ }^{1}$ PPG em Ciência Animal, Universidade Federal Rural do Semi-Árido \\ km 47, BR 110, CEP 59625-900, Mossoró - RN, Brasil \\ ${ }^{2}$ Departamento de Cirurgia, Faculdade de Medicina Veterinária e Zootecnia \\ Universidade de São Paulo, São Paulo - SP, Brasil \\ ${ }^{3}$ Departamento de Ciências Animais \\ Universidade Federal Rural do Semi-Árido, Mossoró - RN, Brasil \\ * Autor para correspondência \\ gleidson_benevides@hotmail.com
}

Submetido em 01/03/2013

Aceito para publicação em 18/06/2013

\section{Resumo}

O preá é um roedor pertencente à família Caviidae. O objetivo deste artigo, considerando a inexistência de informações na literatura, é descrever a origem da veia porta no preá. Foram utilizados 10 espécimes que vieram a óbito por causas naturais no Centro de Multiplicação de Animais Silvestres, Mossoró-RN, Brasil. Esses animais foram incisados medianamente e a veia porta foi canulada inicialmente em sentido cranial e depois em sentido caudal para injeção de solução de látex corado de azul. Em seguida, os animais foram fixados em solução de formol a $10 \%$ e dissecados após $72 \mathrm{~h}$. As tributárias da veia porta no preá foram as veias gastrolienal e gastroduodenal, assim como as veias mesentéricas cranial e caudal.

Palavras-chave: Galea spixii; Roedor; Tributárias; Veia porta

\section{Abstract}

Portal vein of Spix's yellow-toothed cavy (Galea spixii Wagler, 1831). Spix's yellow-toothed cavy is a rodent belonging to the Caviidae family. This paper, taking into account the lack of information in the literature, aims to describe the portal vein origin in Spix's yellow-toothed cavy. One used 10 specimens which died due to natural causes in the Center for Multiplication of Wild Animals, Mossoro, Rio Grande do Norte, Brazil. These animals were medially incised and the portal vein was cranially cannulated at first and, then, caudally cannulated for injecting blue colored latex solution. Subsequently, the animals were fixed in a $10 \%$ formaldehyde solution and dissected after $72 \mathrm{~h}$. The portal vein tributaries in Spix's yellow-toothed cavy were the gastrolienal and gastroduodenal veins, as well as the cranial and caudal mesenteric veins.

Key words: Galea spixii; Portal vein; Rodent; Tributaries 


\section{Introdução}

O preá silvestre do semiárido é um roedor pertencente à família Caviidae. Possui o corpo alongado, coloração uniforme, com a superfície dorsal cinza-escura e ventre branco. A cabeça e os olhos são grandes, as orelhas são curtas e arredondadas. Tem hábito crepuscular, vivem em bandos e alimentam-se de folhas, ramos e frutos de plantas rasteiras, raízes, tubérculos e casca de árvores jovens (MENDES, 1987).

Schwarze e Schröder (1972) observaram que, em animais domésticos, a veia porta é um tronco venoso grosso e ímpar, que recolhe o sangue venoso da maior parte do estômago, intestinos, baço e pâncreas, e o conduz até o fígado. No cavalo, origina-se pela confluência das veias mesentérica cranial, mesentérica caudal e lienal. Nos ruminantes, cervos e caprinos, os troncos venosos que contribuem para formação da veia porta-hepática são o tronco mesentérico comum e o tronco gastrolienal, enquanto que no cão apresenta inúmeras variações. De acordo com Krahmer e Schröder (1979), o sangue carreado pela veia porta contém diversas substâncias procedentes dos alimentos e, possivelmente, materiais nocivos, os quais sofrem as transformações no fígado.

O componente venoso intestinal e as demais tributárias venosas que contribuem para formação da veia porta possuem papel relevante quando analisado do ponto de vista do seu arranjo anatômico, em especial, quanto ao número e à expressão dos seus constituintes. Tal disposição é escassamente referida na literatura, em roedores, destacando-se os trabalhos feitos por Menezes et al. (2001), em cutias, Gameleira e Albuquerque (1998), em mocós, Cooper e Schiller (1975), em cobaias, Hebel e Stromberg (1982), em ratos de laboratório. Vale salientar que este trabalho tem por objetivo fornecer dados para anatomia comparada, em especial, de roedores, baseados na escassez de fontes na literatura acerca da formação da veia porta do preá.

\section{Material e Métodos}

Para desenvolvimento deste estudo foram utilizados 10 preás que vieram a óbito por causas naturais e encontravam-se mantidos em freezer. Os animais foram obtidos no Centro de Multiplicação de Animais Silvestres da Universidade Federal Rural do Semi-Árido (CEMAS / UFERSA), situado no município de Mossoró, no Rio Grande do Norte, licenciado junto ao IBAMA como criadouro cientifico (Registro 1478912).

Os animais foram descongelados e incisados medianamente para abertura das cavidades torácica e abdominal. Em seguida, a veia porta foi canulada inicialmente em sentido do fígado e posteriormente no sentido caudal para injeção de solução de Neoprene látex “650” (Du Pont do Brasil S.A.) corado com pigmento azul (Globo S.A. Tintas e Pigmentos). Os animais foram fixados em solução de formol a 10\% e, após 72 $\mathrm{h}$, dissecados e as tributárias da veia porta identificadas.

As dissecações foram acompanhadas pela elaboração de esquemas representativos dos diferentes arranjos vasculares, para análise e documentação. Simultaneamente foram obtidas imagens fotográficas para dar suporte e ilustrar a exposição dos resultados.

$\mathrm{O}$ estudo baseou-se na nomenclatura adotada pelo International Committee on Veterinary Gross Anatomical Nomenclature (2012) para a denominação das estruturas identificadas e os resultados comparados com a literatura referente a estudos com roedores e outros mamíferos.

\section{Resultados}

O tronco da veia porta, em geral é descrito como sendo formado pela união de vasos que drenam o estômago, duodeno, jejuno, íleo, ceco, cólons (ascendente, transverso e descendente), reto, baço e pâncreas. Nos parágrafos que se seguem as veias que contribuem para formação da veia porta no preá são descritas individualmente.

\section{Veia gastrolienal}

A veia gastrolienal no preá, em todos os casos, estendeu-se caudalmente à direita e foi formada pelas tributárias das veias lienal e gástrica esquerda, sendo que em $10 \%$ dos animais a veia gástrica direita contribuiu para formação da veia gastrolienal.

A veia lienal foi constituída por veias esplênicas, ramos epiploicos (veia gastroepiploica esquerda) e 
ramos pancreáticos, drenando o baço, terço cranial do pâncreas e a curvatura maior do estômago. Esta veia, antes de desembocar na veia porta recebia a veia gástrica esquerda, a qual era responsável pela drenagem da curvatura menor do estômago (Figura 1).

\section{Veia gastroduodenal}

A veia gastroduodenal apresentou-se como um tronco formado pelas veias gastroepiploica direita, gástrica direita e pancreaticoduodenal cranial, mostrouse como tributária da veia porta em $80 \%$ dos animais. As veias gastroepiploica direita e gástrica direita drenavam a parte da grande curvatura do estômago e região fúndica do estômago, respectivamente. Já a veia pancreaticoduodenal cranial era responsável por drenar a porção cranial do duodeno e porção média do pâncreas (Figura 2).

\section{Veia pancreáticoduodnal cranial e gastroepiploica direita}

Em relação às veias pancreaticoduodenal cranial e gastroepiploica direita, verificou-se em $20 \%$ dos animais estudados que estas veias não participaram da formação da veia gastroduodenal, encontrando-se isoladas e drenando suas respectivas regiões diretamente na veia porta, como ilustrado na Figura 3.

\section{Veia gástrica direita}

A veia gástrica direita recolhe o sangue da região fúndica e da curvatura menor do estômago. No preá sua participação, através da drenagem direta na veia porta foi observada em um único animal (10\%) (Figura 3).

\section{Veia mesentérica cranial}

A veia mesentérica cranial, em todos os animais dissecados, apresentou-se como tributária da veia porta, sendo formada pelas veias pancreaticoduodenal caudal (porção caudal do duodeno e porção final do pâncreas), veias jejunais (jejuno), veias cecais, tronco ileocecocólico (íleo, ceco e porção inicial do cólon ascendente) e tronco cólico formado pelas tributárias das veias cólica direita e cólica média que drenam o cólon ascendente e cólon transverso, respectivamente (Figura 4).

FIGURA 1: Formação da veia gastrolienal no preá. Veias esplênicas (1), veia gastroepiploica esquerda (2), ramos pancreáticos (3), tronco lienal (4), veia gástrica esquerda (5), veia gastrolienal (6) e veia porta (7).

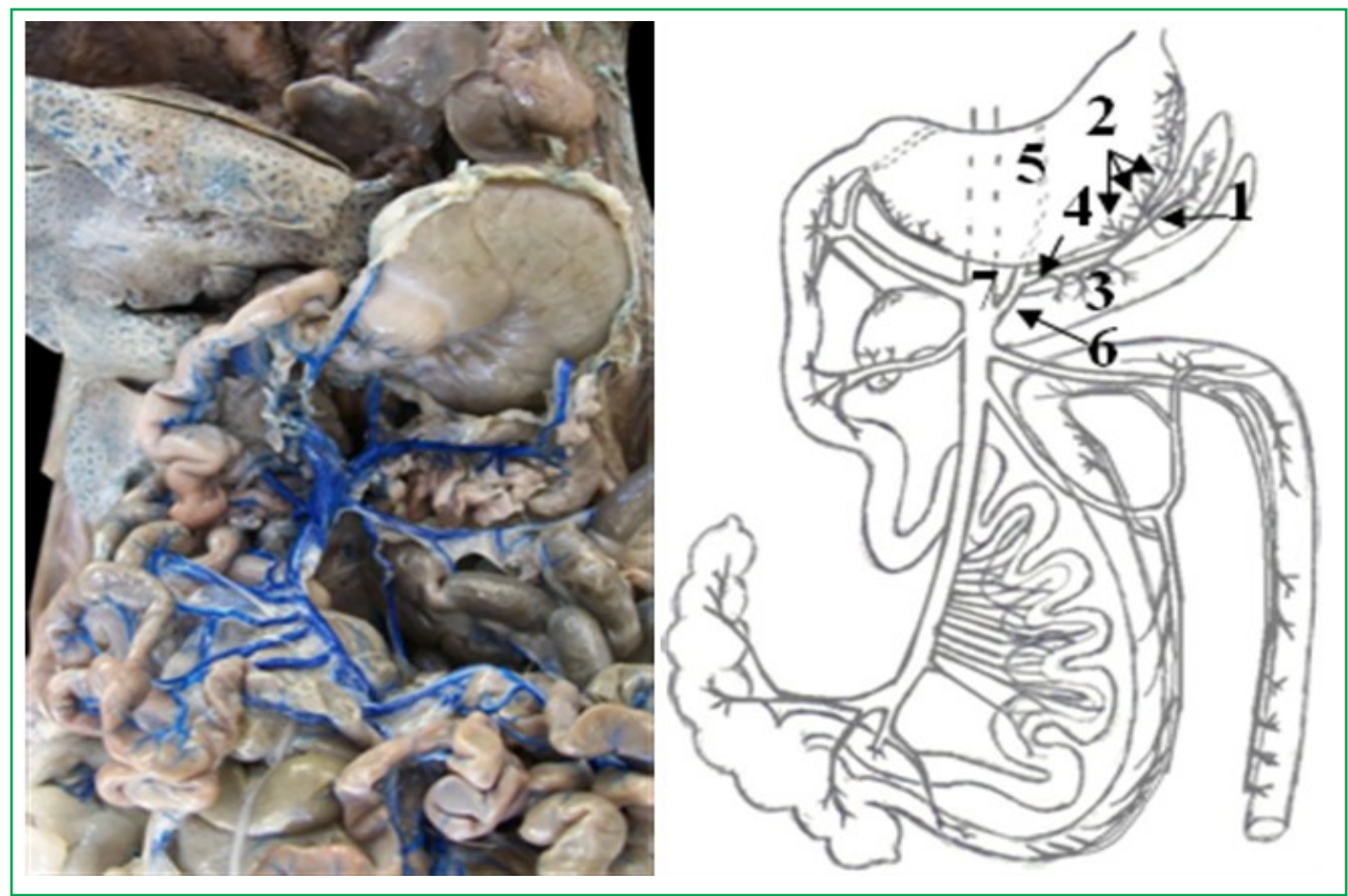


FIGURA 2: Formação da veia gastroduodenal no preá. Veias gastroepiploica direita (1), gástrica direita (2), pancreaticoduodenal cranial (3), veia gastroduodenal (4) e veia porta (5).

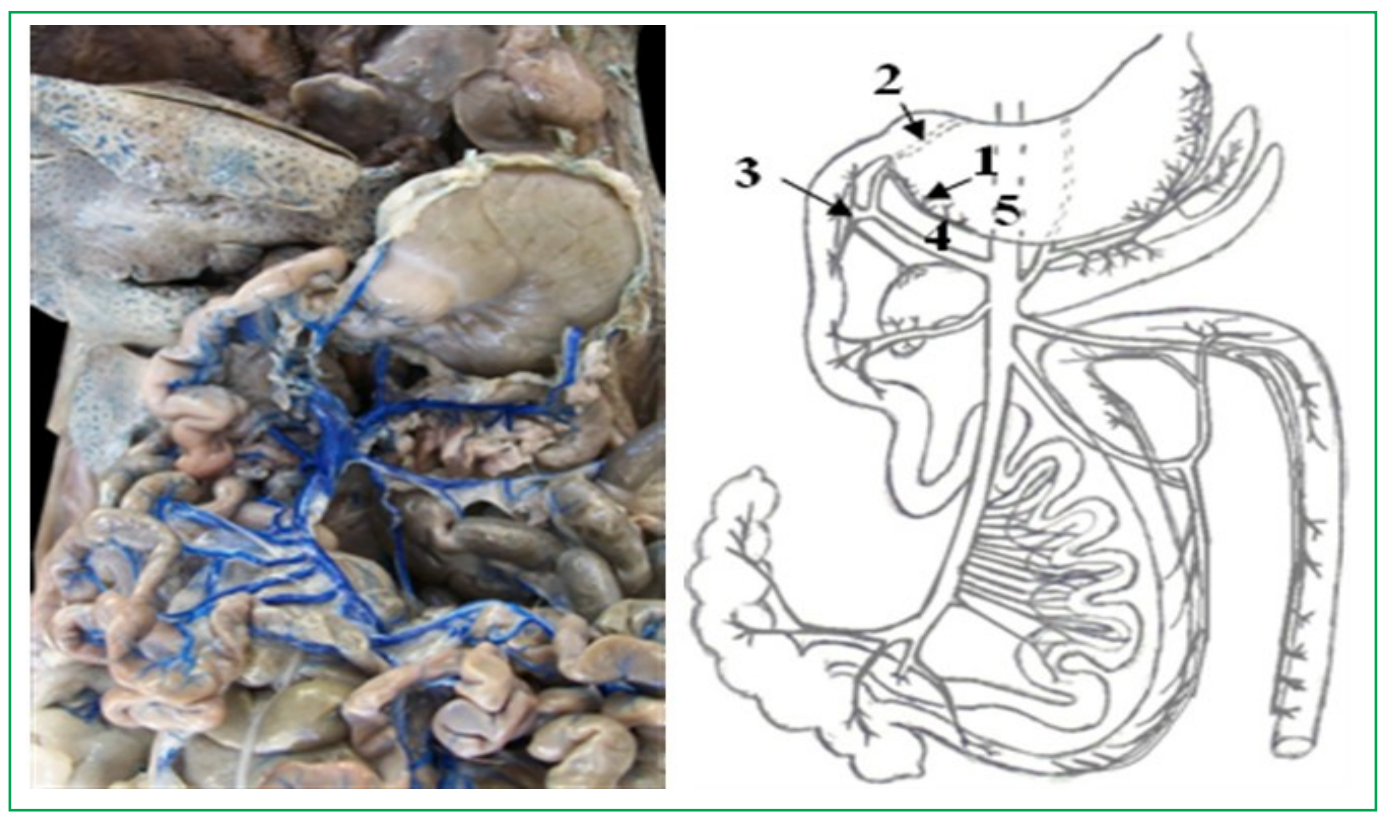

FIGURA 3: Tributárias da veia porta (7). Observam-se as veias mesentéricas cranial (1) e caudal (2), gastrolienal (3), pancreaticoduodenal cranial (4), gastroepiploica direita (5) e gástrica direita (6).

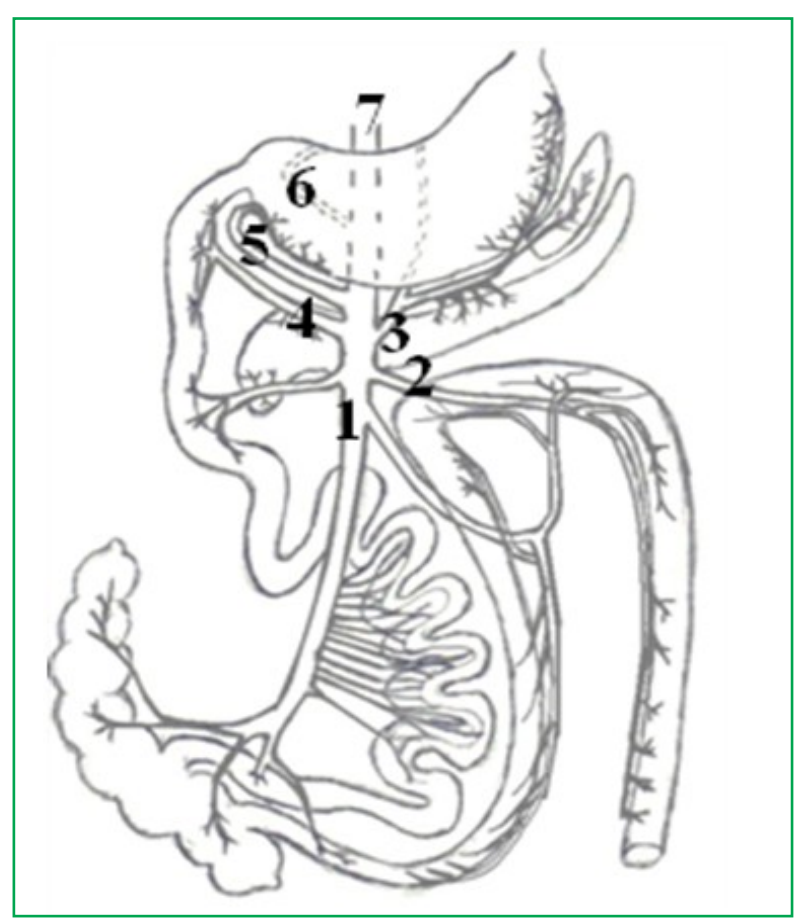

A veia pancreaticoduodenal caudal em $90 \%$ dos casos drena o sangue oriundo da porção final do pâncreas e da porção caudal do duodeno na veia mesentérica cranial, e em 10\% dos animais apresenta-se como tributária da veia porta, drenando a região citada diretamente na veia porta (Figura 5).

As veias jejunais apresentaram-se em número variando entre $10(40 \%), 11(10 \%), 12(20 \%), 13(20 \%)$, e $14(10 \%)$ veias (Figura 4B e 4C). As veias cecais apresentaram-se em número de dois $(30 \%)$, três $(50 \%)$ ou quatro (20\%) veias (Figura 4A).

Quanto ao tronco ileocecólico, este foi formado pela veia ileal, um ramo cecal e um ramo cólico, que drenavam o sangue do íleo, ceco e porção inicial do cólon ascendente (Figura 4B).

\section{Veia mesentérica caudal}

Assim como as veias gastrolienal e mesentérica cranial, a veia mesentérica caudal teve contribuição importante na formação do tronco da veia porta, contribuindo com a formação desta em todos os casos estudados (100\%). Esta veia resultou da confluência das veias cólica esquerda (Figura 6B), responsável pela 
FIGURA 4: Tributárias da veia mesentérica cranial no preá. Em A, o ramo cólico (1), veia ileal (2), tronco ileocólico (3), veias cecais (4), jejunais (5), o tronco cólico (6), a veia pancreaticoduodenal caudal (7), a mesentérica cranial (8) e a veia porta (9). Em B, as veias jejunais (1), cólicas média (2) e direita (3), tronco cólico (4), veia mesentérica cranial (5), pancreaticoduodenal caudal (6) e veia porta (9).
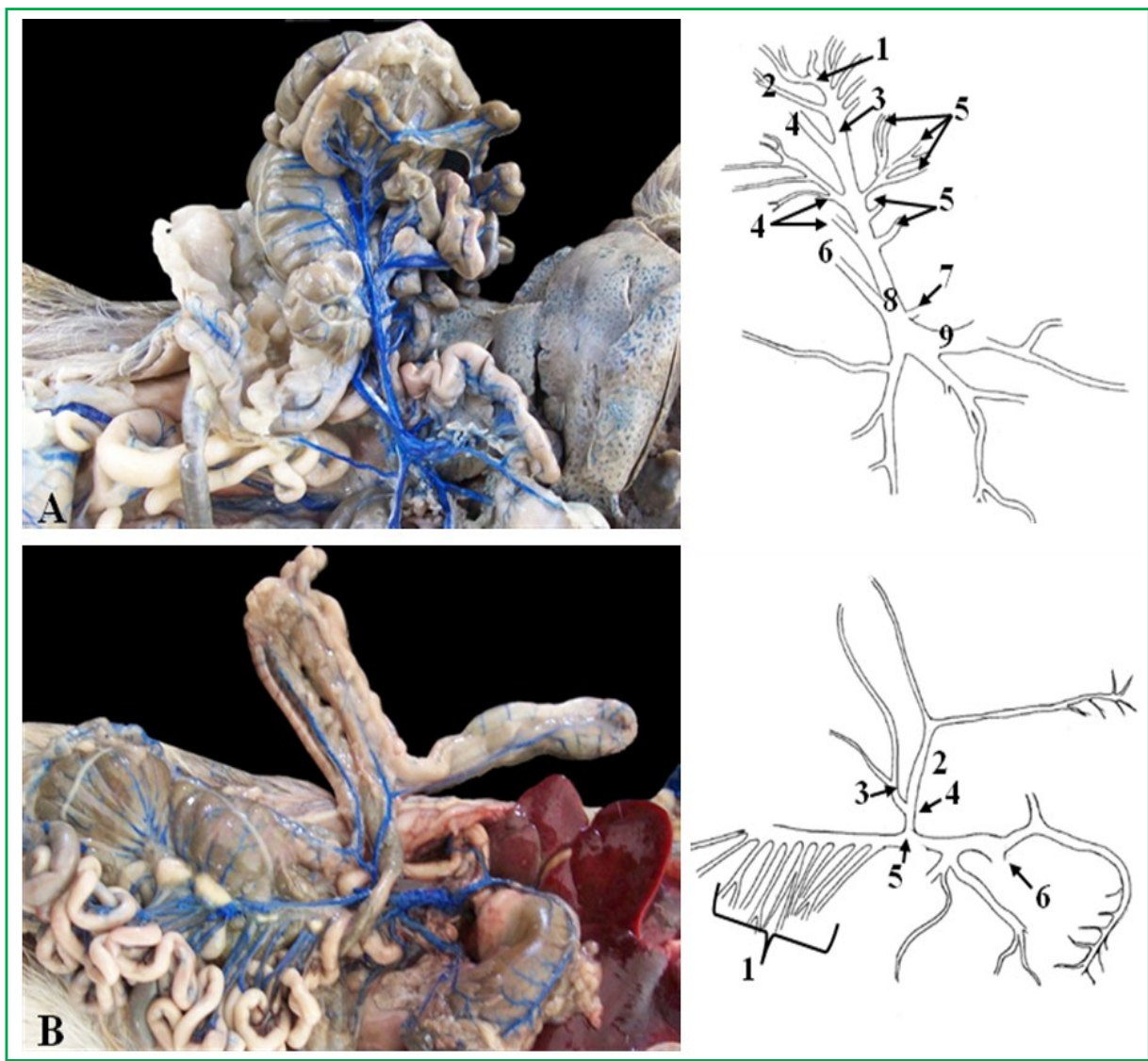

FIGURA 5: Tributárias da veia porta no preá. Veias mesentérica cranial (1), mesentérica caudal (2), pancreaticoduodenal caudal (3), gastrolienal (4), gastroduodenal (5) e veia porta (6).

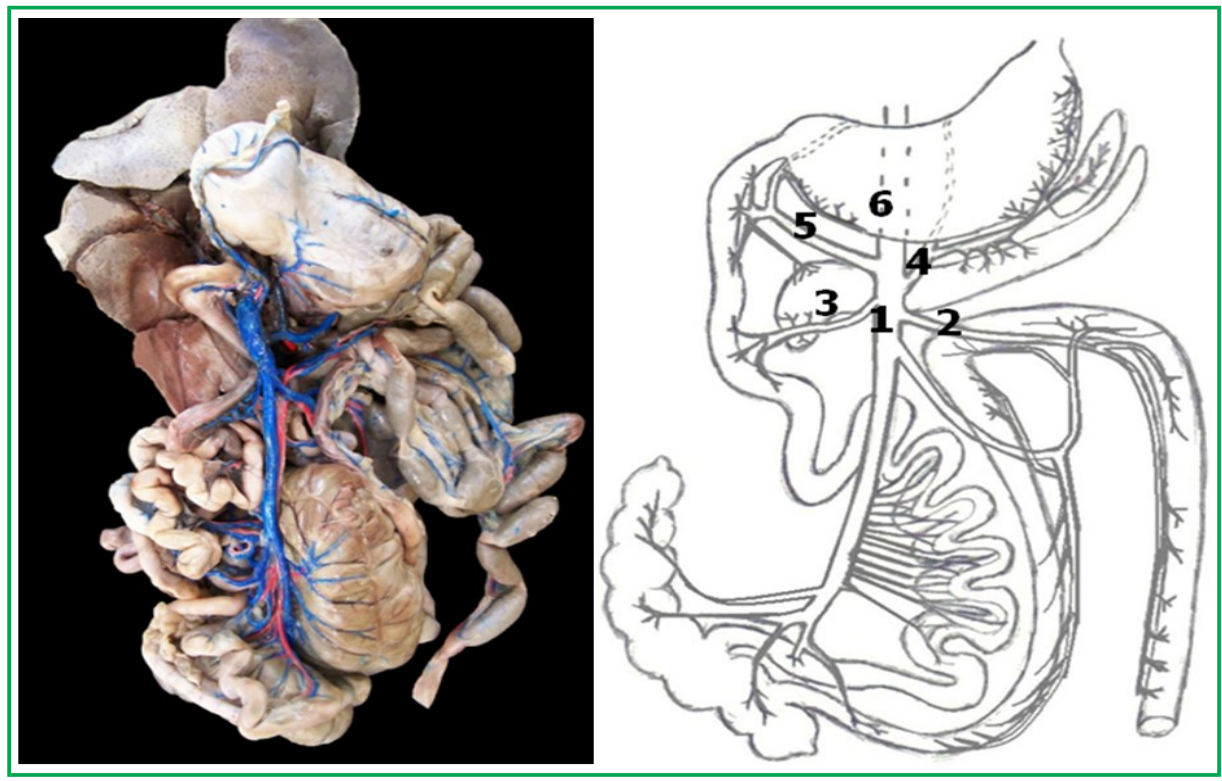


FIGURA 6: Formação da veia mesentérica caudal no preá. Em A, observa-se a veia retal cranial (1) confluindo para veia mesentérica caudal (2), tributária da veia porta (3). Em B, a veia cólica esquerda (1) drenando para a mesentérica caudal (2). Identifica-se ainda as veias mesentérica cranial (3), gastrolienal (4), gastroduodenal (5) e a veia porta (6).

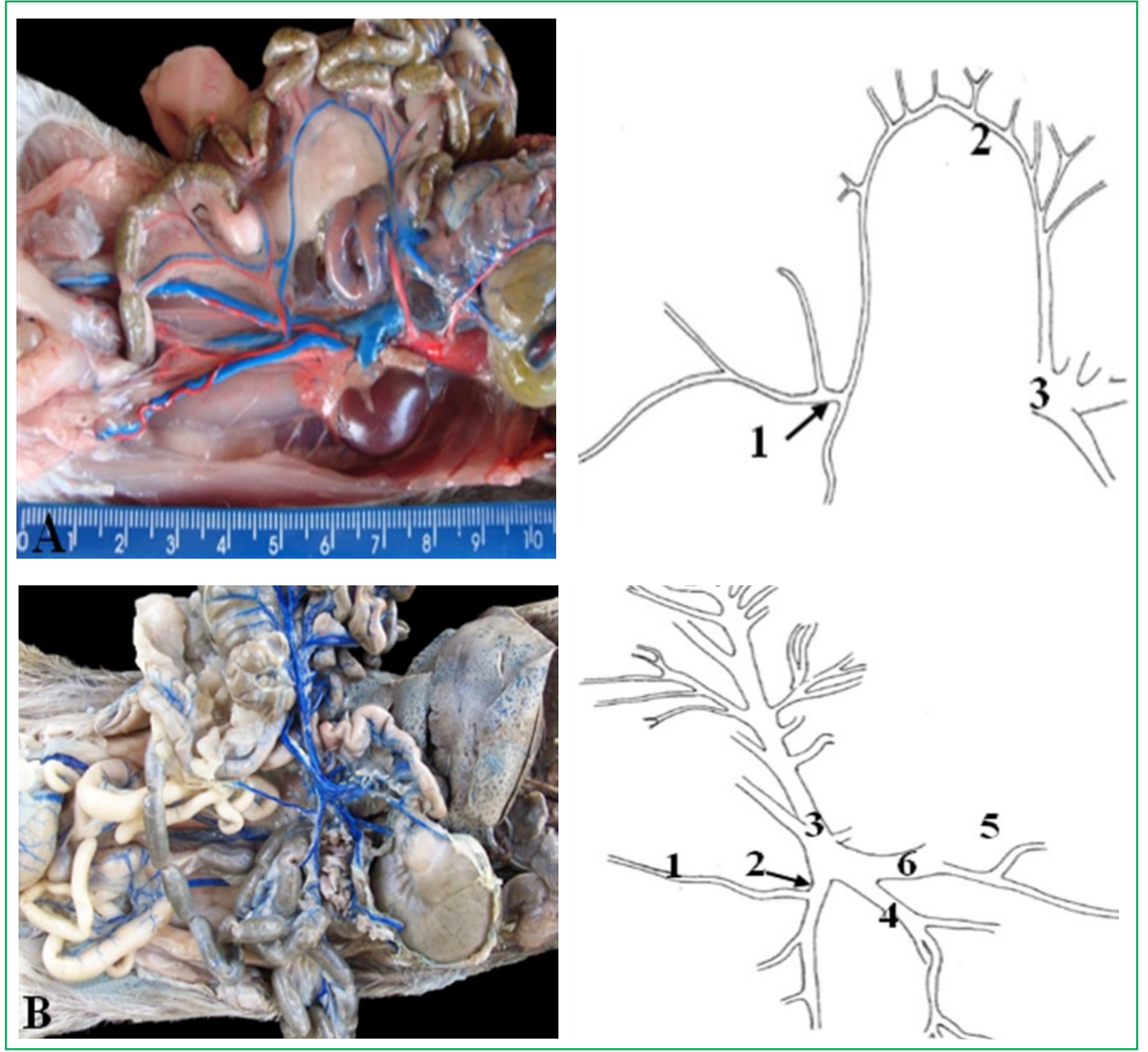

drenagem do cólon descendente, e veias retais (veia retal cranial, retais medianas e retal caudal) (Figura 6A)

\section{Discussão}

Na literatura, informações sobre as tributárias da veia porta são abordadas por Schwarze e Schröder (1972) e Barone e Bortolami (1981), em animais domésticos, como sendo um vaso que conduz o fluxo sanguíneo de todos os órgãos do aparelho digestório inclusive do fígado.

\section{Tributárias da veia porta}

No preá verificou-se que a veia porta é um vaso calibroso formado pela união de tributárias que drenam o estômago, duodeno, jejuno, íleo, ceco, cólons, reto, pâncreas e baço, a exemplo do que ocorre com outros mamíferos (Tabela 1).

De acordo com Getty (1981), os afluentes terminais do sistema porta-hepático, é formado pelas veias gastroduodenal, esplênica, pancreaticoduodenal caudal, mesentéricas cranial e caudal e por ramos venosos do 
TABELA 1: Tributárias da veia porta nas diferentes espécies de roedores.

\begin{tabular}{|c|c|c|}
\hline Espécie & Tributárias & Literatura \\
\hline Preá & $\begin{array}{l}\text { Mesentéricas cranial e caudal, gastrolienal e } \\
\text { gastroduodenal }\end{array}$ & \\
\hline Camundongo & $\begin{array}{l}\text { Tronco de mesentérica cranial e caudal, gastroduodenal } \\
\text { e esplênica }\end{array}$ & Hebel e Stromberg (1982) \\
\hline Coelho & $\begin{array}{c}\text { Mesentérica caudal, cólica esquerda, cólica direita } \\
\text { e cólica média, mesentérica cranial, tronco da veia } \\
\text { jejunal, pancreaticoduodenal e gastrolienal }\end{array}$ & Birk et al. (2006) \\
\hline Cutia & Tronco mesentérico comum e lienal & Menezes et al. (2001) \\
\hline Mocó & $\begin{array}{l}\text { Mesentérica cranial, gastroduodenal, gastrolienal e } \\
\text { gástrica esquerda }\end{array}$ & Gameleira e Albuquerque (1998) \\
\hline Porquinho da índia & $\begin{array}{l}\text { Mesentéricas cranial e caudal, esplênica e } \\
\text { gastroduodenal }\end{array}$ & Cooper e Schiller (1975) \\
\hline Rato de laboratório & $\begin{array}{l}\text { Mesentéricas cranial e caudal, gastroepiploica direita, } \\
\text { pancreaticoduodenal cranial e gastroesplênica }\end{array}$ & Chiasson (1969) \\
\hline
\end{tabular}

pâncreas. Já Bruni e Zimmerl (1977) relatam que a veia porta é formada a partir da confluência das veias mesentéricas cranial e caudal e da veia esplênica, recebendo constantemente a veia gastroduodenal e ocasionalmente um vaso pancreático.

Segundo Menezes et al. (2001), o tronco da veia porta na cutia é essencialmente formada pela veia lienal e pelo tronco mesentérico comum, mas pode ser formada apenas pelas veias lienal e mesentérica cranial, descrição anatômica não observada no preá. Estes autores citam ainda que além das raízes principais, o tronco da veia porta da cutia recebe como tributárias as veias pancreaticoduodenal cranial, gástrica direita, e a veia gastroepiploica direita. No preá, a veia pancreaticoduodenal cranial, encontra-se, juntamente com as veias gastroepiploica direita e gástrica direita, formando um tronco comum que desemboca na veia porta, mas também se observa que as mesmas podem não se unirem drenando isoladamente o órgão para a veia porta.

Gameleira e Albuquerque (1998), analisando as tributárias da veia porta no mocó, afirmam que esta é formada em maior frequência pela veia mesentérica cranial e que, após, constituída recebe como tributárias as veias gastroduodenal, gastrolienal e gástrica esquerda ou em menor frequência, pode resultar da união das veias mesentérica cranial, mesentérica caudal e lienal.
Torna-se importante destacar, que no preá, a veia gástrica esquerda e a veia lienal unem-se antes de afluir para veia porta.

Da mesma forma, os resultados obtidos para o preá diferem daqueles observados por Cook (1965) em ratos de laboratório quando o mesmo refere-se que a veia porta é formada a partir da união das veias lienal e mesentérica cranial. Quanto aos resultados obtidos por Chianson (1969), estudando o rato branco, ao mencionar que a veia porta é formada pelas veias mesentérica cranial, mesentérica caudal, gastroepiplo ica direita, pancreaticoduodenal cranial e gastroesplênica, é importante afirmar que em preás a veia porta esteve formada pelas veias gastroepiploica direita e pancreaticoduodenal cranial, em apenas $20 \%$ das observações, isoladamente.

Cooper e Schiller (1975) descrevendo as tributárias da veia porta em cobaias afirmam que esta é formada pela confluência das veias mesentéricas cranial e caudal, "esplênica" e gastroduodenal. Torna-se importante ressaltar que nos estudos com preá optou-se por distinguir a participação da veia esplênica e da veia gástrica esquerda, já que estas confluem para formar um tronco que denominamos de gastrolienal. $\mathrm{O}$ fato dos autores terem citado apenas a participação da veia esplênica, na formação da veia porta, pode estar associado à não formação deste tronco ou por terem 
optado por critérios de nomenclatura diferentes dos adotados neste trabalho.

Hebel e Stromberg (1982), em estudo da veia porta hepática, no rato de laboratório, concluem que a mesma é formada pelas veias gastroduodenal, esplênica e um tronco de mesentérica cranial e caudal, sendo a veia gastroduodenal formada pela junção da veia pancreticoduodenal cranial e gastroepiploica direita. No preá, além destes achados, soma-se ainda à formação da veia gastroduodenal a veia gástrica direita.

Ao descreverem sobre os afluentes da veia porta de coelhos, Barone et al. (1973) afirmam que esta origina-se a partir de afluentes venosos, correspondentes ao tronco ileocólico, a veia jejunal comum, a veia pancreaticoduodenal caudal, a veia gastroduodenal e ao tronco gastrolienal, diferindo do observado no preá e em outros roedores estudados por Hebel e Stromberg (1982), Gameleira e Albuquerque (1998), Menezes et al. (2001) e por Birck et al. (2006), especialmente pelo fato de não ter sido observado a participação do tronco ileocólico e da veia jejunal comum como afluentes da veia porta. Birk et al. (2006), por sua vez, relata que em coelhos contribuem para a formação da veia porta-hepática, a veia gastrolienal, a veia pancreaticoduodenal, tronco da veia jejunal, a veia mesentérica cranial, as veias cólicas esquerda, direita e média e a veia mesentérica caudal, contrariando o padrão normal para a formação da veia porta, que em geral, é formada pelas veias mesentérica cranial gastroduodenal, gastrolienal mesentérica cranial e caudal, com pequenas variações entre as espécies.

Quanto aos resultados obtidos no preá, com relação às tributárias da veia gastrolienal ou lienal, estes diferem dos achados de Greene (1963) e Hebel e Stromberg (1982) quando mencionam em ratos, que esta recebe como tributárias, ramos pancreáticos e a veia gástrica esquerda, pois no preá, além destas tributarias observouse a participação da veia gastroepiploica esquerda formando a veia gastrolienal. Já Cook (1965) conclui que no camundongo este vaso, recebe como tributárias as veias gástrica esquerda e lienopancreática.

Na cutia, Menezes et al. (2001) relatam que são tributárias da veia lienal, os ramos pancreáticos, a veia gástrica esquerda e ramos epiploicos e veias gástricas curtas. Porém, para o preá, as veias gástricas curtas não foram identificadas como tributárias da veia gastrolienal. Birk et al. (2006), por sua vez, citam no coelho que a veia gastrolienal recebe ramos pancreáticos, esplênicos e as veias gástricas direita e esquerda, contudo nos resultados descritos observou-se para a espécie em estudo que a veia gástrica direita participou em menor frequência como tributária da veia gastrolienal.

A análise da literatura citada, quando comparada aos resultados encontrados para o preá sugerem que não existe um padrão comum de vasos formadores da veia gastrolienal, pelo menos para roedores já que a maioria da literatura consultada trata-se de estudos com roedores.

\section{Veia gastroduodenal}

Com relação formação da veia gastroduodenal no preá, esta se originou, principalmente, a partir das veias gastroepiploicas direita, pancreaticoduodenal cranial e a veia gástrica direita, resultados semelhantes aos achados descritos por Smith (1999) em tratado sobre anatomia do cão, onde o mesmo cita essa formação como o padrão da espécie. Em roedores, no entanto, (HEBEL; STROMBERG, 1982; MENEZES et al., 2001; BIRCK et al., 2006), citam apenas as veias gastroepiploica direita e pancreaticoduodenal cranial, como tributárias da veia gastroduodenal. Torna-se importante destacar que, no preá, à exemplo do observado por Chiasson (1969) em estudos com ratos brancos e por Menezes et al. (2001) em estudos com cutias, as veias gastroepiploica direita e pancreaticoduodenal cranial podem convergir diretamente à veia porta.

\section{Veias mesentéricas cranial e caudal}

As veias mesentéricas cranial e caudal participaram como tributárias da veia porta, em todos os animais estudados. Tais resultados também são citados por Hebel e Stromberg (1982) e Menezes et al. (2001), para ratos e cutias, respectivamente. Se considerada a importância fisiológica destas veias para a drenagem sanguínea dos intestinos, é de se supor que em outros grupos de animais esse fato ocorra com muita frequência. 


\section{Veia mesentérica cranial}

Ao discorrerem sobre as tributárias da veia mesentérica cranial, Cooper e Schiller (1975), no porquinho-da-índia, Heath e House (1970), em coelhos, e Schwarze e Schröder (1972) e Sisson e Grossman (1973), em animais domésticos, descrevem este vaso como sendo formado pelas veias jejunais, pelas veias pancreaticoduodenal caudal e ileocólica. Greene (1963), Chiasson (1969), Hebel e Stromberg (1982), em estudos com ratos, e Birck et al. (2006), em coelhos, citam ainda as veias cecais, a cólica direita e cólica média. No preá, observou-se o mesmo comportamento vascular para a formação da veia mesentérica cranial, ressaltando-se que as veias cólica direita e cólica média convergem formando um tronco único que drena na veia mesentérica cranial.

A veia pancreaticoduodenal caudal, de acordo com Greene (1963), Cook (1965) e Hebel e Stromberg (1982), em ratos, Menezes et al. (2001), na cutia, e Birk et al. (2006), no coelho, converge para a veia mesentérica cranial. Barone et al. (1973), por sua vez, citam que este vaso aflui diretamente na veia porta. $\mathrm{Na}$ espécie estudada, verificou-se todas estas formações. Contudo, os achados de Barone et al. (1973), foram os menos frequentes, aparecendo em apenas 20\% dos animais dissecados.

Quanto às veias jejunais, estas apresentaram comportamento semelhante ao descritos em roedores por Greene (1963), Chiasson (1969), Hebel e Stromberg (1982), Menezes et al. (2001) e Birck et al. (2006), quando citam que estas afluem diretamente para veia mesentérica cranial. Em contrapartida, diferi dos resultados de Barone et al. (1973), em coelho, quando citam que a veia jejunal drena o sangue diretamente para veia porta.

Nos roedores analisados, verificou-se que as veias cecais eram muito calibrosas, possivelmente devido ao ceco ser bem desenvolvido, e ainda que desembocavam separadamente ao longo da veia mesentérica cranial, fato observado por Menezes et al. (2001), na cutia. Diferentemente do verificado em preás, Greene (1963), Cook (1965), Chiasson (1969), Barone et al. (1973) e Birck et al. (2006) concluem, estudando diferentes espécies de roedores, que o ceco é drenado pela veia ileocólica. Já Hebel e Stromberg (1982) citam que no rato de laboratório as veias cecais drenam para veia ileocecocólica, diferentemente do verificado no preá.

A veia cólica direita no preá, apresenta-se drenando o sangue proveniente do cólon ascendente, igualmente como descrito, em roedores, por Greene (1963), Hebel e Stromberg (1982), Menezes et al. (2001) e Birk et al. (2006). Já com relação à veia cólica média, esta apresenta origem semelhante aos relatos de Hebel e Stromberg (1982) no rato de laboratório, Menezes et al. (2001), na cutia, e por Birck et al. (2006), no coelho, ao descreverem que esta veia drena a região do cólon transverso.

Da mesma forma que o verificado para a formação do tronco ileocólico, no preá, Menezes et al. (2001), na cutia, afirmam que este tronco constitui-se de ramos ileais, ramos cecais e um ramo destinado a porção inicial do cólon ascendente. Já Bruni e Zimmerl (1977) e Goshal et al. (1981), em tratado de animais domésticos, descrevem a participação das veias cólicas como tributárias do tronco ileocecocólico e ileocólico, respectivamente.

\section{Veia mesentérica caudal}

No preá, a veia mesentérica caudal apresenta-se recebendo as veias retal cranial, ramos cólicos e a veia cólica esquerda, comportamento semelhante ao citado por Hebel e Stromberg (1982) no rato de laboratório e por Menezes et al. (2001) na cutia. No entanto, este último, cita ainda que a veia mesentérica caudal pode afluir na veia lienal, diferindo do observado no preá, já que no mesmo esta veia comporta-se como tributária da veia porta. Já Greene (1963) e Cook (1965), em ratos de laboratório, aludem que a veia mesentérica caudal converge para a veia mesentérica cranial, diferentemente dos resultados encontrado no preá.

Quanto à veia mesentérica caudal, Getty (1981) descreve no equino, esta como sendo uma tributária da veia porta, recebe as veias cólica média, cólica esquerda e a veia retal cranial. Já Cooper e Schiller (1975) relatam que em cobaias a veia mesentérica caudal inicia-se como um plexo venoso em torno do reto, correndo 
paralelamente à artéria retal cranial, como a veia retal cranial, a qual une-se as veias retal caudal e retais medianas. A veia retal cranial, dentro do mesentério corre cranialmente como veia cólica esquerda, e entra dorsolateralmente defronte à veia porta e a veia pancreaticoduodenal caudal. Da mesma forma, Birck et al. (2006) descrevem que no coelho a veia mesentérica caudal tem inicio a partir de um plexo venoso, situado junto à parede do reto, e ao correr paralelamente à artéria retal cranial, denomina-se de veia retal cranial. Esta veia ao seguir em sentido cranial recebe como tributárias as veias cólica esquerda e cólica média. Em contrapartida, os resultados encontrados no preá diferem dos citados por Getty (1981) e Birck et al. (2006), já que na espécie estudada a veia cólica média, em nenhum momento, esteve drenando para a veia mesentérica caudal.

Em conclusão podemos observar que a veia porta do preá apresenta-se como um vaso calibroso formado por tributárias que drenam o estômago, duodeno, jejuno, íleo, ceco, cólons, reto, pâncreas e baço, a exemplo do que se observa em outros mamíferos, com algumas diferenças. As tributárias da veia porta do preá corresponderam às veias gastrolienal, gastroduodenal e veias mesentéricas cranial e caudal. Em algumas situações a veia porta do preá teve contribuição das veias pancreaticoduodenal cranial, gastroepiploica direita e a veia gástrica direita.

\section{Referências}

BARONE, R.; BORTOLAMI, R. Anatomie compareé des mammifères domestiques. Vol. 3. Bologna: Edagricole, 1981. p. $652 \mathrm{p}$.

BARONE, R.; PAVAUX, C.; BUN, P. C.; CUQ, P. Atlas d'anatomie du lapin. Paris: Masson, 1973. 219 p.

BIRCK, A. J.; MIGLINO, M. A.; MACHADO, G. V.; SANTOS, T. C. Formação da veia porta-hepática em coelhos da raça Nova Zelândia Branco (Oryctolagus cuniculus Linnaeus, 1758). Brazilian Journal of Veterinary Research and Animal Science, São Paulo, v. 43, n. 1, p. 87-94, 2006.
BRUNI, A. C.; ZIMMERL, U. Anatomia degli animali domestici. Vol. 2 . 2 ed. Milano: Casa Editrice Dottor Francesco Vallardi, 1977. $595 \mathrm{p}$.

CHIASSON, R. B. Laboratory anatomy of the white rat. 2. ed. Arizona: Brown Company Publishers, 1969. 81 p.

COOK, M. J. The anatomy of the laboratory mouse. London: Academic Press, 1965. 143 p.

COOPER, G.; SCHILLER, A. L. Anatomy of the guinea pig. Cambridge: Harvard University Press, 1975. 417 p.

GAMELEIRA, J. A. L.; ALBUQUERQUE, J. F. G. Contribuição ao estudo da anatomia da veia porta e suas tributárias no mocó (Kerodon rupestris) criados em cativeiro. In: SEMINÁRIO INTERNO DO PIBIC/UFERSA, 4, 1998, Mossoró. Resumos... Mossoró: UFERSA, 1998. Versão eletrônica.

GETTY, R. Anatomia dos animais domésticos. Vol. 1. 5. ed. Rio de Janeiro: Guanabara Koogan, 1981. 1185 p.

GHOSHAL, N. G.; KOCK, T.; POPESCO, P. The venous drainage of the domestic animals. Philadelphia: W. B. Saunders, 1981. $230 \mathrm{p}$.

GREENE, E. C. Anatomy of the rat. Vol. 2. New York: American Philosophical Society, 1963. 370 p.

HEATH, T.; HOUSE, B. Origin and distribution of portal blood in the cat and rabbit. American Journal of Anatomy, Philadelphia, v. 127, n. 2, p. 71-80, 1970.

HEBEL, R.; STROMBERG, M. V. Anatomy and embriology of the laboratory rat. Wörthesee: Bio Med. Verlag, 1982. 270 p.

INTERNATIONAL COMMITTEE ON VETERINARY GROSS ANATOMICAL NOMENCLATURE. Nomina Anatomica Veterinária. 5. ed. Knoxville: World Association on Veterinary Anatomist, 2012. 177 p.

KRAHMER, R.; SCHRÖDER, L. Anatomía de los animales domésticos. Zaragoza: Editorial Acribia, 1979. 144 p.

MENDES, B. V. Plantas e animais para o Nordeste. Rio de Janeiro: Globo, 1987. 167 p.

MENEZES, D. J. A.; CARVAlHO, M. A. M.; CAVALCANTE FILHO, M. F.; SOUZA, W. M. Configuração do sistema venoso portal na cutia (Dasyprocta aguti, Rodentia). Brazilian Journal of Veterinary Research Animal Science, São Paulo, v. 38, n. 6, p. 263-266, 2001.

SCHWARZE, E.; SCHRÖDER, L. Compendio de anatomia veterinaria. Vol. 3. Zaragoza: Acríbia, 1972. 313 p.

SISSON, S.; GROSSMAN, J. D. Anatomia de los animales domésticos. 4. ed. Barcelona: Salvat, 1973. 952 p.

SMITH, B. J. Canine anatomy (The national veterinary medical series). Philadelphia: Williams \& Wilkins, 1999. 429 p. 